\title{
Decomposition characteristics of organic materials and their effects on labile and recalcitrant organic carbon fractions in a semi-arid soil under plastic mulch and drip irrigation
}

\author{
HU Juan, WU Jinggui ${ }^{*}$, QU Xiaojing \\ College of Resource and Environmental Science, Jilin Agricultural University, Changchun 130118, China
}

\begin{abstract}
Labile organic carbon (LC) and recalcitrant organic carbon (RC) are two major fractions of soil organic carbon (SOC) and play a critical role in organic carbon turnover and sequestration. The aims of this study were to evaluate the variations of LC and RC in a semi-arid soil (Inner Mongolia, China) under plastic mulch and drip irrigation after the application of organic materials (OMs), and to explore the effects of OMs from various sources on LC and RC by probing the decomposition characteristics of OMs using in-situ nylon mesh bags burying method. The field experiment included seven treatments, i.e., chicken manure (CM), sheep manure (SM), mushroom residue (MR), maize straw (MS), fodder grass (FG), tree leaves (TL) and no OMs as a control (CK). Soil LC and RC were separated by Huygens D's method (particle size-density), and the average soil mass recovery rate and carbon recovery rate were above 95\%, which indicated this method was suitable for carbon pools size analysis. The LC and RC contents significantly $(P<0.01)$ increased after the application of OMs. Moreover, LC and RC contents were $3.2 \%-8.6 \%$ and $5.0 \%-9.4 \%$ higher in 2016 than in 2015 . The applications of CM and SM significantly increased $(P<0.01)$ LC content and LC/SOC ratio, whereas they were the lowest after the application of TL. However, SOC and RC contents were significantly higher $(P<0.01)$ after the applications of TL and MS. The correlation analysis indicated the decomposition rate of OMs was positively related with LC content and LC/SOC ratio. In addition, lignin, polyphenol, WOM (total water-soluble organic matter), WHA (water-soluble humic acid), HSL (humic-like substance) and HAL (humic acid-like) contents in initial OMs played important roles in SOC and RC. In-situ nylon mesh bags burying experiment indicated the decomposition rates of CM, SM and MS were significantly higher than those of MR, FG, and TL. Furthermore, MS could result in more lignin derivatives, WHA, and HAL polymers in shorter time during the decomposition process. In conclusion, the application of MS in the semi-arid soil under a long-term plastic mulch and drip irrigation condition could not only improve soil fertility, but also enhance soil carbon sequestration.
\end{abstract}

Keywords: organic materials; labile organic carbon; recalcitrant organic carbon; decomposition characteristics; plastic mulch; drip irrigation; Inner Mongolia

Citation: HU Juan, WU Jinggui, QU Xiaojing. 2018. Decomposition characteristics of organic materials and their effects on labile and recalcitrant organic carbon fractions in a semi-arid soil under plastic mulch and drip irrigation. Journal of Arid Land, 10(1): 115-128. https://doi.org/10.1007/s40333-017-0035-1

\footnotetext{
${ }^{*}$ Corresponding author: WU Jinggui (E-mail: wujingguiok@163.com)

Received 2017-04-06; revised 2017-10-31; accepted 2017-11-13

(C) Xinjiang Institute of Ecology and Geography, Chinese Academy of Sciences, Science Press and Springer-Verlag GmbH Germany, part of Springer Nature 2018
} 


\section{Introduction}

Soil organic carbon (SOC) plays an important role in supplying plant nutrients, enhancing cation exchange capacity, improving soil aggregation and water retention, and supporting soil biological activity (Loveland and Webb, 2003; Lal, 2004; Sparling and Schipper, 2004; Haynes, 2005). At the same time, SOC is an index of sustainable land management (Nandwa, 2001) and is critical in determining response to $\mathrm{N}$ and $\mathrm{P}$ fertilization. Although labile organic carbon (LC) fraction accounts for a small part of total SOC, but it directly involves in soil biochemical processes and plays a vital role in soil health (Haubensak et al., 2002; McLauchlan and Hobbie, 2004; Cookson et al., 2005). Separation techniques of LC can be classified as physical, chemical, and biological methods. Especially, chemical method is more common used in previous studies. LC fractions included water-soluble organic carbon (WOC), dissolved organic carbon (DOC), microbial biomass carbon (MBC), particulate organic carbon (POC), and the permanganate oxidized carbon (POXC) have been identified by chemical method (Meng et al., 2013; Plaza-Bonilla et al., 2014). However, physical method does less damage to organic carbon structure than that of chemical method, and the separation of components can reflect the structure and function of undisturbed SOC (Zhang et al., 2011). According to carbon cycle characteristics in Markov Chain Monte Carlo (MCMC) model (Müller et al., 2004), Huygens et al. (2007) have recently improved the soil separation method of Meijboom et al. (1995). They asserted SOC could be divided into LC and recalcitrant organic carbon (RC), which could be directly determined by this physical method. LC and $\mathrm{RC}$ are two important components of SOC, and their ratios to SOC (i.e., LC/SOC and $\mathrm{RC} / \mathrm{SOC}$ ) could be used as indicators to describe SOC turnover and sequestration (Yu et al., 2015).

Management strategies to research the variation of SOC components have recently received much attention (Knoblauch et al., 2011; Du et al., 2013; Troy et al., 2013). One important strategy for sustainable agriculture production systems was the application of organic materials (OMs) into soils (Schmidt et al., 2011). Gougoulias et al. (2014) and Liu et al. (2016) have shown that the application of OMs contributed lots to LC content, which was mainly due to the OMs inputted into soil provide carbon source for soil microbial. Liang (2012) and Chen et al. (2015) also found that the application of OMs could significantly affect the contents of MBC, POC, and DOC. Moreover, Li et al. (2016) indicated that soil DOC and MBC contents after the applications of straw, mushroom residue, and manure were significantly improved. A lot of studies have been conducted on the effects of the application of OMs on LC fractions using the chemical method; For example, Singh et al. (2009) found that the quality of OMs had an important influence on short-term soil carbon dynamic. The amounts of SOC and LC were closely related to the types and properties of exogenous OMs (Manna et al., 2005). However, relatively few attempts have been made on LC and RC fractions separated by Huygens D's method (2007) and the relationship between chemical compositions of OMs and SOC fractions. Integrating the water saving of drip irrigation and evaporation reducing of plastic film mulch was more suitable for improving the water utilization efficiency, especially in semi-arid areas in western China. In recent years, the application areas of plastic mulch and drip irrigation in Inner Mongolia have been about $4.686 \times 10^{5} \mathrm{hm}^{2}$. Jiang et al. (2014) and Yin et al. (2014) found that plastic film mulch could change the physical, chemical and biological properties of soils, as well as improve the decomposition of soil organic matter and the transformation and release of soil nutrients, thus increasing soil nutrient availability and soil fertility. Li et al. (2007) found that the biomass and yield of corn increased after plastic film mulch, which resulted in the increase of corn residue returned into soil. Li et al. (2009) also found that plastic film mulch promoted the decomposition of organic carbon and in turn decreased the light fraction organic carbon content of topsoil. In a word, lots of studies were carried out to research the effects of plastic mulch and drip irrigation on LC in different soils. However, little information is available in the effects of plastic mulch and drip irrigation on LC and RC.

The aim of this study was to evaluate the variations of LC and RC separated by Huygens D's method in a semi-arid soil under plastic mulch and drip irrigation after the application of six 
different origins of OMs, including natural organic materials (maize straw, fodder grass, and tree leaves), livestock manures (chicken manure and sheep manure), and half-decomposed organic materials (mushroom residue). In addition, in-situ nylon mesh bags burying experiment was conducted to explore the decomposition characteristics and variations in the chemical compositions of different OMs. We hypothesized that the application of OMs would increase SOC, LC, and RC contents, and affect the turnover and sequestration of SOC in a semi-arid soil under plastic mulch and drip irrigation condition. Moreover, the decomposition rate and chemical compositions of OMs would play important roles in SOC fractions.

\section{Materials and methods}

\subsection{Experimental site}

The experiment was conducted in Tumuji Town $\left(46^{\circ} 17^{\prime} \mathrm{N}, 123^{\circ} 00^{\prime} \mathrm{E}\right)$, which is located at Jalaid Banner, Hinggan League, Inner Mongolia, China, and belongs to semi-arid areas. The annual average temperature is $4.0^{\circ} \mathrm{C}$, the mean annual precipitation is $300-450 \mathrm{~mm}$, and the frost-free period is approximate $150 \mathrm{~d}$. The average annual hours of sun exposure is $2592 \mathrm{~h}$, and the total amount of solar radiation is $5362.46 \mathrm{MJ} /\left(\mathrm{m}^{2} \cdot \mathrm{a}\right)$. The effective accumulated temperature $\geq 10^{\circ} \mathrm{C}$ is about $2700^{\circ} \mathrm{C}-3300^{\circ} \mathrm{C}$. The soil is classified as Chernozem, with a $\mathrm{pH}$ of 8.2 and containing 19.8 $\mathrm{g} / \mathrm{kg}$ of organic matter, $6.55 \mathrm{mg} / \mathrm{kg}$ of available phosphate, $51.36 \mathrm{mg} / \mathrm{kg}$ of available potassium, and $84.82 \mathrm{mg} / \mathrm{kg}$ of available nitrogen.

\subsection{Experimental design and soil sampling}

\subsubsection{Field experiment with the application of OMs}

The field experiment was conducted in May 2015 and 2016. The OMs used including chicken manure (CM), sheep manure (SM), mushroom residue (MR), maize straw (MS), fodder glass (FG), tree leaves (TL), and with no OMs as control (CK). CM and SM were collected from chicken-breeding farm and sheep-breeding farm, respectively. MR was the residue of edible fungus culture medium produced with corn as raw material. MS was maize straw, and TL was poplar leaves. FG was collected from Jalaid Banner pasture. The basic properties of initial OMs were shown in Table 1 . The variety of maize used was XianYu 335. The area of each plot was 5 $\mathrm{m} \times 10 \mathrm{~m}$. The field was randomly designed with three replicates for each treatment. The mechanized coated drip irrigation cultivation technique was used in planting process. OMs were fertilized to ridge artificially after ridging both in 2015 and 2016. The height of the ridge was 10 $\mathrm{cm}$. The inputted quantity of carbon was $7719 \mathrm{~kg} \mathrm{C} / \mathrm{hm}^{2}$ and each organic material treatment was equivalent in 2015 and 2016. The application rates were $33,151 \mathrm{~kg} / \mathrm{hm}^{2}$ for CM, 27,708 kg/hm

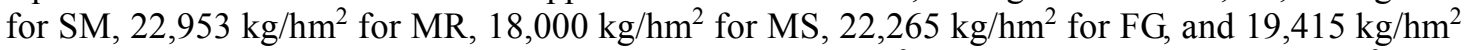
for TL. Each plot was fertilized with urea $\left(210 \mathrm{~kg} \mathrm{~N} / \mathrm{hm}^{2}\right)$, superphosphate $\left(67 \mathrm{~kg} \mathrm{P} / \mathrm{hm}^{2}\right)$ and potassium chloride $\left(87 \mathrm{~kg} \mathrm{~K} / \mathrm{hm}^{2}\right)$. Soil samples were collected from the junction of ridge and furrow in 0-20 cm depth in October 2015 and 2016. Five samples of each plot followed "S" method. Then the samples were air-dried and passed through a 2-mm sieve after removal of crop residues and stones.

\subsubsection{Field experiment with in-situ nylon mesh bags burying}

The field experiment with in-situ nylon mesh bags burying was conducted at the same time and the field management was similar to the application of OMs. There were totally six treatments, i.e., CM, SM, MR, MS, FG, and TL. Every treatment consisted of three replicates, and each plot covered an area of $1.7 \mathrm{~m} \times 3.6 \mathrm{~m}$. The raw materials of MR, TL, CM, and SM were crushed into crumbs, while materials of MS and FG were cut into segments in about 2-3 cm long. Each kind of OMs was weighed $20 \mathrm{~g}$ and was placed into the 300 mesh nylon bags in a size of $20 \mathrm{~cm} \times 15 \mathrm{~cm}$ and then sealed. Totally, 24 parts of nylon mesh bags were buried in each plot. Nylon mesh bags were tiled with no overlaps directly below the drip irrigation belt at $20-\mathrm{cm}$ intervals in $10 \mathrm{~cm}$ deep soil. Three nylon mesh bags from each plot were randomly collected at 30,60, 90, 120, 150, 180, 
360 , and 540 days after burial, which were carried back to the laboratory and set aside after clearing up.

Lignin and cellulose were measured by Van Soest acid detergent fiber (Van Soest, 1963). Organic $\mathrm{C}$ was measured by an exogenous thermal process with potassium dichromate (Walkley and Black, 1934). Polyphenol was measured by ferrous tartrate (Turkmen et al., 2006). Total N was determined by Kjeldahl method. The water-soluble organic matter and humic-like substance fractions were extracted according to the method of Wu et al. (2004).

Table 1 Basic properties of the initial organic materials

\begin{tabular}{ccccccc}
\hline Index & $\begin{array}{c}\text { Chicken } \\
\text { manure } \\
(\mathrm{CM})\end{array}$ & $\begin{array}{c}\text { Sheep } \\
\text { manure } \\
(\mathrm{SM})\end{array}$ & $\begin{array}{c}\text { Mushroom } \\
\text { residue } \\
(\mathrm{MR})\end{array}$ & $\begin{array}{c}\text { Maize straw } \\
(\mathrm{MS})\end{array}$ & $\begin{array}{c}\text { Fodder grass } \\
(\mathrm{FG})\end{array}$ & $\begin{array}{c}\text { Tree leaves } \\
(\mathrm{TL})\end{array}$ \\
\hline Organic C (g/kg) & $232.84 \pm 2.30^{\mathrm{e}}$ & $278.58 \pm 2.01^{\mathrm{d}}$ & $336.29 \pm 3.34^{\mathrm{c}}$ & $428.85 \pm 2.56^{\mathrm{a}}$ & $346.68 \pm 4.18^{\mathrm{c}}$ & $397.57 \pm 1.21^{\mathrm{b}}$ \\
Total N (g/kg) & $15.19 \pm 0.61^{\mathrm{a}}$ & $9.82 \pm 0.38 \mathrm{~b}^{\mathrm{c}}$ & $11.06 \pm 0.53^{\mathrm{b}}$ & $6.13 \pm 0.72^{\mathrm{c}}$ & $16.75 \pm 1.05^{\mathrm{a}}$ & $8.72 \pm 0.68^{\mathrm{bc}}$ \\
C/N & $15.33 \pm 0.82^{\mathrm{e}}$ & $28.37 \pm 1.64^{\mathrm{c}}$ & $30.42 \pm 1.33^{\mathrm{c}}$ & $69.96 \pm 1.51^{\mathrm{a}}$ & $20.70 \pm 0.97^{\mathrm{d}}$ & $45.59 \pm 1.36^{\mathrm{b}}$ \\
Lignin (\%) & $2.29 \pm 0.33^{\mathrm{e}}$ & $2.60 \pm 0.75^{\mathrm{e}}$ & $6.90 \pm 0.42^{\mathrm{c}}$ & $5.30 \pm 0.18^{\mathrm{d}}$ & $8.49 \pm 0.83^{\mathrm{b}}$ & $11.50 \pm 0.67^{\mathrm{a}}$ \\
Cellulose (\%) & $7.02 \pm 0.93^{\mathrm{e}}$ & $20.53 \pm 1.24^{\mathrm{c}}$ & $12.76 \pm 1.55^{\mathrm{d}}$ & $37.81 \pm 2.17^{\mathrm{a}}$ & $25.64 \pm 2.00^{\mathrm{b}}$ & $13.47 \pm 0.64^{\mathrm{d}}$ \\
Hemicellulose (\%) & $4.16 \pm 0.22^{\mathrm{d}}$ & $14.13 \pm 0.72^{\mathrm{b}}$ & $4.35 \pm 0.21^{\mathrm{d}}$ & $23.68 \pm 1.15^{\mathrm{a}}$ & $16.25 \pm 1.07^{\mathrm{b}}$ & $8.89 \pm 0.58^{\mathrm{c}}$ \\
Polyphenol (\%) & $0.69 \pm 0.05^{\mathrm{b}}$ & $0.75 \pm 0.08^{\mathrm{b}}$ & $0.72 \pm 0.09^{\mathrm{b}}$ & $0.88 \pm 0.07^{\mathrm{b}}$ & $0.81 \pm 0.04^{\mathrm{b}}$ & $1.05 \pm 0.03^{\mathrm{a}}$ \\
Lignin/N & $1.51 \pm 0.32^{\mathrm{d}}$ & $2.65 \pm 0.19^{\mathrm{d}}$ & $6.24 \pm 0.24^{\text {cd }}$ & $8.65 \pm 0.43^{\mathrm{b}}$ & $5.07 \pm 0.41^{\mathrm{cd}}$ & $13.19 \pm 0.92^{\mathrm{a}}$ \\
Quality class & $\mathrm{IM}$ & $\mathrm{IM}$ & $\mathrm{IM}$ & $\mathrm{IM}$ & $\mathrm{IM}$ & $\mathrm{IM}$ \\
\hline
\end{tabular}

Note: IM, intermediate quality. Data with the same lowercase letter within the same row do not differ significantly at the $5 \%$ level according to the least significant difference test. Mean \pm standard error.

\subsection{Separation method of labile organic carbon (LC) and recalcitrant organic carbon (RC)}

The extracted soil was subjected to LC and RC fractions using the Huygens D's method. Each sample was treated three times and the specific steps were listed as follows: $50 \mathrm{~g}$ air-dried soil passing through a $2-\mathrm{mm}$ sieve was placed on the $0.25-\mathrm{mm}$ sieve, and then wet by deionized water. Put the set of sieves $(0.25-, 0.15-$ and $0.05-\mathrm{mm}$ sieves) into the wet sieve barrel and added water to immerse the soil on the top of the $0.25-\mathrm{mm}$ sieve, then wet-sieve it with a sieving machine in $30 \mathrm{~min}$. Size fractions lying on sieves of $0.25-\mathrm{mm}$ and $0.15-\mathrm{mm}$ were washed into a bucket and swirled with injected deionized water. Upper turbid liquid was poured out and collected until the washing solution was clear to separate the macro organic matter $(>0.15 \mathrm{~mm} \mathrm{MOM})$ and mineral fraction $(>0.15 \mathrm{~mm} \mathrm{MF})$ by decantation. Then, we collected the MOM, MF, 0.05-0.15 mm fraction and $<0.05 \mathrm{~mm}$ fraction (centrifuged with $3000 \mathrm{r} / \mathrm{min}$ in $5 \mathrm{~min}$ ). Each fraction was oven-dried at $55^{\circ} \mathrm{C}$ and weighed. Dried soils were grounded with planetary ball mill and normally stored for further carbon analysis.

LC was carbon content in terms of MOM in $1 \mathrm{~kg}$ of original soil. RC was the sum of carbon content in terms of MF, $0.50-0.15 \mathrm{~mm}$ fraction and $<0.05 \mathrm{~mm}$ fraction in $1 \mathrm{~kg}$ of original soil. Mass recovery referred to the percentage of the sum of different soil grades weight comprising total soil weight $(50 \mathrm{~g})$. In other words, carbon recovery meant the sum of carbon content in different soil grades which represented the carbon content in the total amount of soil.

\subsection{Data and statistical analyses}

Decomposition percentage $(\%)=($ mass of initial OMs-mass of residue OMs $) /$ mass of initial OMs $\times 100 \%$,

Cellulose decomposition percentage $(\%)=($ content of initial OMs-content of residue $\mathrm{OMs}$ )/content of initial OMs $\times 100 \%$.

Residual quantities of OMs in decomposition process were fitted by exponential equation:

$$
y=a+b \times \mathrm{e}^{-k \times t},
$$


where $y(\mathrm{~g})$ is residual quantity at time $t ; k$ is constant of decomposition rate calculated by the least-squares method, indicating the decomposing speed level; $b(\mathrm{~g})$ is mass lost; and $a(\mathrm{~g})$ is asymptote value of $y$ when $t$ is $\propto$.

$$
\mathrm{C} \text { released quantities }=\left(C_{0} \times M_{0}-C_{t} \times M_{t}\right) \times 10^{-3} \text {, }
$$

where $C_{0}$ is $\mathrm{C}$ content of initial OMs $(\mathrm{g} / \mathrm{kg}) ; M_{0}$ is mass of initial OMs $(\mathrm{g}) ; C_{t}$ is C content of OMs at time $t(\mathrm{~g} / \mathrm{kg})$; and $M_{t}$ is mass of OMs at time $t(\mathrm{~g})$.

$\mathrm{C}$ released quantities from $\mathrm{OMs}$ in decomposition process were fitted by the first-order kinetic equation:

$$
C_{t}=C_{0} \times\left(1-\mathrm{e}^{-k_{0} \times t}\right)
$$

where $k_{0}$ is constant of carbon decomposition rate calculated by the least-squares method.

The results were initially collected with Excel 2010 (Microsoft, Redmond, WA, USA). All analyses were carried out with three replicates. The data were analyzed in the analysis of variance (ANOVA) procedure. Multiple comparisons were made under Duncan's new multiple ranges test (DMRT). Significant differences between treatments were determined at $95 \%$ and $99 \%$ levels of probability. Graphical material was prepared using Origin 2007 (Originlab, Northampton, USA).

\section{Results}

\subsection{Soil organic carbon (SOC)}

Compared with $\mathrm{CK}$, the SOC contents increased significantly $(P<0.01)$ after the application of OMs (Fig. 1). Both in 2015 and 2016, SOC contents followed the descending order $\mathrm{TL}>\mathrm{MS}>\mathrm{FG}>\mathrm{MR}>\mathrm{SM}>\mathrm{CM}$, whereas $\mathrm{SOC}$ contents after the application of OMs in 2016 were $6.7 \%-12.6 \%$ higher than those in 2015. Compared with CK, SOC contents after the applications of TL and MS respectively increased $39.5 \%$ and $36.2 \%$ in 2016. SOC contents after the application of TL were $9.5 \%, 15.0 \%, 19.2 \%$, and $20.7 \%$ higher than those of FG, MR, SM and $\mathrm{CM}$ in $2016(P<0.01)$. Meanwhile, SOC contents after the application of MS were $6.9 \%, 12.2 \%$, $16.3 \%$, and $17.8 \%$ higher than those of FG, MR, SM and CM in 2016, respectively $(P<0.01)$. However, SOC content after the application of TL was $2.5 \%$ higher than that of MS $(P<0.05)$ in 2016.
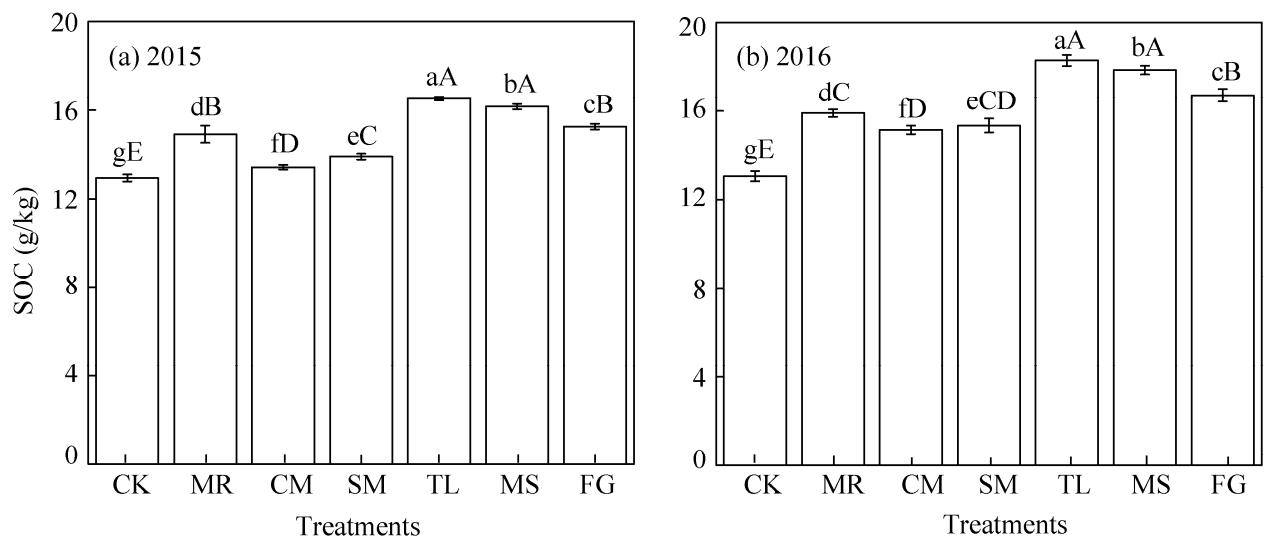

Fig. 1 Soil organic carbon (SOC) contents after the application of OMs (organic materials) in 2015 and 2016. The error bars mean standard deviations. The different lowercase and capital letters above the bars mean the significances at $P<0.05$ and $P<0.01$ levels in the same year among different fertilization treatments. CK, control; MR, mushroom residue; CM, chicken manure; SM, sheep manure; TL, tree leaves; MS, maize straw; FG, fodder grass. Abbreviations are the same as follows.

\subsection{Labile organic carbon (LC) and recalcitrant organic carbon (RC)}

The average mass recovery rate and carbon recovery rate were $95.53 \%(94.51 \%-96.32 \%)$ and $95.87 \%(94.54 \%-96.25 \%)$, respectively after separation. The separation method was simple and suitable for carbon pools size analysis, for the errors were controlled at a reasonable range. 
Compared with $\mathrm{CK}$, the LC and RC contents significantly increased $(P<0.01)$ after the application of OMs (Table 2). Moreover, LC and RC contents were $3.2 \%-8.6 \%$ and $5.0 \%-9.4 \%$ higher in 2016 than in 2015, respectively. Compared with CK, LC contents in soil after the applications of CM and SM increased the most, and were $28.9 \%$ and $30.7 \%$, respectively in 2016 . Furthermore, LC contents in soil after the applications of MS, MR and FG were $10.8 \%, 9.4 \%$ and $8.5 \%$ higher than that of TL $(P<0.01)$ in 2016 , respectively. Compared with $\mathrm{CK}, \mathrm{RC}$ contents after the applications of TL and MS, respectively increased $38.4 \%$ and $33.0 \%$ in 2016 . RC contents after the application of TL were $11.7 \%, 17.0 \%, 21.8 \%$, and $27.5 \%$ higher than those of FG, MR, SM and CM in 2016, respectively $(P<0.01)$. RC contents after the application of MS were $7.3 \%$, $12.3 \%, 17.0 \%$, and $22.4 \%$ higher than those of $\mathrm{FG}, \mathrm{MR}, \mathrm{SM}$ and $\mathrm{CM}$ in 2016, respectively $(P<0.01)$. RC content after the application of TL was $4.2 \%$ higher than that of MS $(P<0.01)$ in 2016 .

Table 2 LC and RC contents after the application of OMs in 2015 and 2016

\begin{tabular}{|c|c|c|c|c|c|c|c|c|}
\hline SOC component & Year & CK & MR & $\mathrm{CM}$ & SM & TL & MS & FG \\
\hline \multirow{2}{*}{$\mathrm{LC}(\mathrm{g} / \mathrm{kg})$} & 2015 & $1.10 \pm 0.01^{\mathrm{eE}}$ & $1.40 \pm 0.02^{\mathrm{cC}}$ & $1.49 \pm 0.01^{\mathrm{aA}}$ & $1.43 \pm 0.01^{\mathrm{bB}}$ & $1.31 \pm 0.01^{\mathrm{dD}}$ & $1.40 \pm 0.02^{\mathrm{cC}}$ & $1.34 \pm 0.01^{\mathrm{cC}}$ \\
\hline & 2016 & $1.19 \pm 0.03^{\mathrm{dC}}$ & $1.46 \pm 0.06^{\mathrm{bB}}$ & $1.54 \pm 0.02^{\mathrm{abA}}$ & $1.56 \pm 0.03^{\mathrm{aA}}$ & $1.34 \pm 0.02^{\mathrm{cB}}$ & $1.48 \pm 0.05^{\mathrm{bB}}$ & $1.45 \pm 0.04^{\mathrm{bB}}$ \\
\hline \multirow{2}{*}{$\mathrm{RC}(\mathrm{g} / \mathrm{kg})$} & 2015 & $11.32 \pm 0.09^{\mathrm{fE}}$ & $13.08 \pm 0.24^{\mathrm{dC}}$ & $11.53 \pm 0.10^{\mathrm{fE}}$ & $12.06 \pm 0.12^{\mathrm{eD}}$ & $14.68 \pm 0.06^{\mathrm{aA}}$ & $14.26 \pm 0.11^{\mathrm{bB}}$ & $13.34 \pm 0.08^{\mathrm{cC}}$ \\
\hline & 2016 & $11.60 \pm 0.23^{\mathrm{gG}}$ & $13.73 \pm 0.15^{\mathrm{dD}}$ & $12.59 \pm 0.11^{\mathrm{fE}}$ & $13.19 \pm 0.110^{\mathrm{eE}}$ & $16.06 \pm 0.181^{\mathrm{aA}}$ & $15.42 \pm 0.142^{\mathrm{bB}}$ & $14.37 \pm 0.269^{c C}$ \\
\hline
\end{tabular}

Note: SOC, soil organic carbon; LC, labile organic carbon; RC, recalcitrant organic carbon; OMs, organic materials. The different lowercase and capital letters within the same row indicate the significances at $P<0.05$ and $P<0.01$ levels in the same year among different fertilization treatments. Mean \pm standard error.

Two-way ANOVA revealed that OMs treatments and years were both the main factors influencing SOC, LC, and RC contents (Table 3). The interactions between OMs treatments and years were significant for SOC and RC contents; however, it was not significant for LC content.

Table 3 Significant effects of OMs treatments, years and their interactions on SOC, LC and RC contents

\begin{tabular}{|c|c|c|c|c|c|c|c|c|c|}
\hline \multirow{2}{*}{ Main effect } & \multicolumn{3}{|c|}{$\mathrm{SOC}$} & \multicolumn{3}{|c|}{$\mathrm{LC}$} & \multicolumn{3}{|c|}{$\mathrm{RC}$} \\
\hline & Mean square & $F$ value & Sig. & Mean square & $F$ value & Sig. & Mean square & $F$ value & Sig. \\
\hline OMs treatment $(\mathrm{O})$ & 14.58 & 316.42 & $* *$ & 0.094 & 115.71 & $* *$ & 12.30 & 511.94 & $* *$ \\
\hline Year (Y) & 17.02 & 369.54 & $* *$ & 0.051 & 62.52 & $* *$ & 9.56 & 398.06 & $* *$ \\
\hline $\mathrm{O} \times \mathrm{Y}$ & 0.472 & 10.25 & $* *$ & 0.002 & 1.90 & NS & 0.206 & 8.57 & $* *$ \\
\hline
\end{tabular}

Note: ** indicates significance at $P<0.01$ level; NS, not significant.

\subsection{Ratios of labile organic carbon and recalcitrant organic carbon to soil organic carbon (LC/SOC and RC/SOC)}

Allocation proportions of LC fractions were obviously different after the application of OMs (Fig. 2). Compared with $\mathrm{CK}, \mathrm{LC} / \mathrm{SOC}$ ratio after the applications of $\mathrm{CM}$ and $\mathrm{SM}$ significantly $(P<0.01)$ increased $31.7 \%$ and $21.7 \%$ in 2015 , and significantly $(P<0.01)$ increased $11.5 \%$ and $11.6 \%$ in 2016 , respectively. LC/SOC ratio significantly $(P<0.01)$ decreased after the application of TL in 2015, and significantly $(P<0.01)$ decreased after the applications of TL and MS in 2016. However, compared with $\mathrm{CK}, \mathrm{RC} / \mathrm{SOC}$ ratio after the applications of $\mathrm{CM}$ and $\mathrm{SM}$ reduced and had no significant differences in 2015 and 2016. Compared with six kinds of OMs, RC/SOC ratio after the application of TL was the highest, and followed by the MS.

\subsection{Pearson's correlation coefficient $(r)$ between chemical compositions of OMs and SOC fractions}

A correlation analysis was conducted to explore the relationships between chemical compositions of OMs and SOC fractions (Table 4). As a result, the most important chemical compositions of SOC content were the lignin $(r=0.709, P<0.01)$, WOM $(r=0.754, P<0.01)$, WHA $(r=0.652$, $P<0.05)$, HSL $(r=0.685, P<0.05)$, polyphenol $(r=0.655, P<0.05)$, and HAL $(r=0.619, P<0.05)$ in 
(a) $2015 \square \mathrm{CL} \square \mathrm{LC}$ Uा: RC

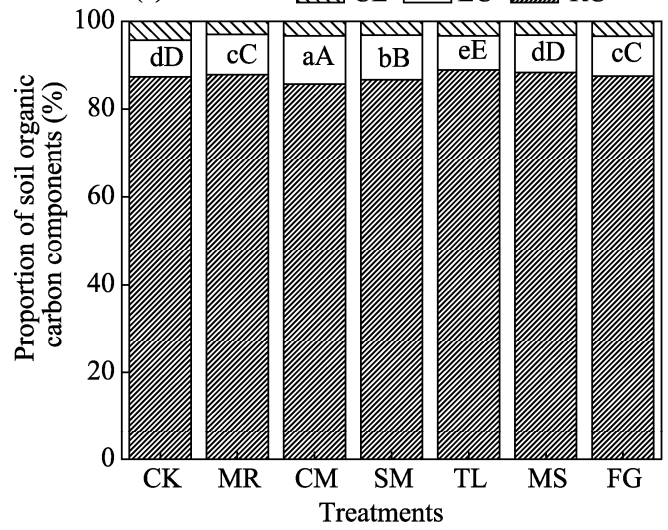

(b) 2016

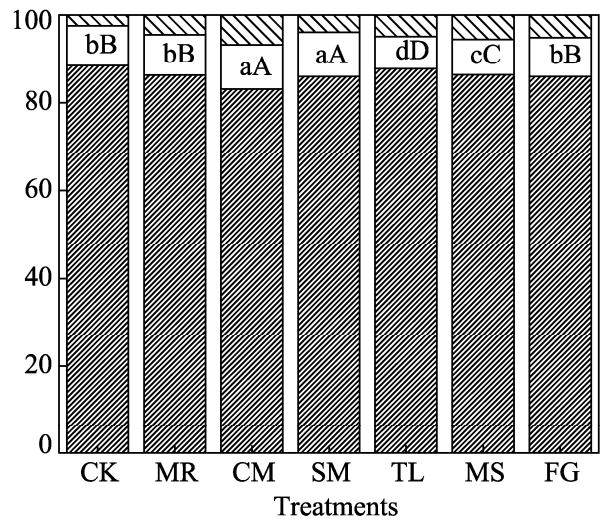

Fig. 2 Proportion of soil organic carbon components after the application of OMs in 2015 and 2016. CL, carbon loss quantities in separation; LC, labile organic carbon; RC, recalcitrant organic carbon. The different lowercase and capital letters indicate significances at $P<0.05$ and $P<0.01$ levels among different fertilization treatments.

OMs. LC content showed a negative relationship with $\mathrm{C} / \mathrm{N}$ ratio $(r=-0.817, P<0.01)$ and WHA $(r=-0.640, P<0.01)$. RC content showed a positive relationship with lignin $(r=0.633, P<0.05)$, polyphenol $(r=0.642, P<0.05)$, lignin $/ \mathrm{N}$ ratio $(r=0.627, P<0.05)$, WOM $(r=0.733, P<0.01)$, WHA $(r=0.750, P<0.01)$, HSL $(r=0.747, P<0.01)$ and HAL $(r=0.725, P<0.01)$. The most important factor affecting the $\mathrm{LC} / \mathrm{SOC}$ ratio was $\mathrm{C} / \mathrm{N}$ ratio $(r=-0.718, P<0.01)$. Lignin $(r=0.647, P<0.05)$ and lignin/ $\mathrm{N}$ ratio $(r=0.738, P<0.01)$ played important roles in $\mathrm{RC} / \mathrm{SOC}$ ratio. In addition, a positive relationship was found between decomposition rates of OMs and LC content $(r=0.507$, $P<0.05)$, and $\mathrm{LC} / \mathrm{SOC}$ ratio $(r=0.734, P<0.01)$.

Table 4 Pearson's correlation coefficient $(r)$ between chemical compositions of OMs and SOC fractions in 2016

\begin{tabular}{cccccc}
\hline SOC fraction & SOC & LC & RC & LC/SOC & RC/SOC \\
\hline Organic C & 0.350 & 0.231 & 0.483 & 0.118 & 0.181 \\
Total N & 0.133 & 0.243 & 0.076 & 0.396 & 0.119 \\
C/N & 0.005 & $-0.817^{* *}$ & 0.092 & $-0.718^{* *}$ & 0.399 \\
Cellulose & 0.309 & 0.493 & 0.303 & 0.271 & 0.418 \\
Hemicellulose & 0.348 & 0.392 & 0.369 & 0.331 & 0.278 \\
Lignin & $0.709^{* *}$ & 0.411 & $0.633^{*}$ & 0.456 & $0.647^{*}$ \\
Polyphenol & $0.655^{*}$ & 0.411 & $0.642^{*}$ & 0.318 & 0.408 \\
Lignin/N & 0.514 & 0.459 & $0.627^{*}$ & 0.504 & $0.738^{* *}$ \\
WOM & $0.754^{* *}$ & -0.169 & $0.773^{* *}$ & 0.266 & -0.049 \\
WLOM & 0.286 & 0.182 & 0.292 & 0.260 & 0.320 \\
WHA & $0.652^{*}$ & $-0.640^{*}$ & $0.750^{* *}$ & 0.099 & -0.231 \\
HSL & $0.685^{*}$ & -0.344 & $0.747^{* *}$ & 0.036 & -0.088 \\
FAL & 0.520 & 0.333 & 0.514 & 0.148 & -0.220 \\
HAL & $0.619^{*}$ & -0.240 & $0.725^{* *}$ & -0.100 & 0.086 \\
Decomposition rate & 0.218 & $0.507^{*}$ & 0.262 & $0.734^{* *}$ & -0.055 \\
\hline Not & & & &
\end{tabular}

Note: LC/SOC, ratio of labile organic carbon to soil organic carbon; RC/SOC, ratio of recalcitrant organic carbon to soil organic carbon; WOM, total water-soluble organic matter; WLOM, water-soluble litter-molecular organic matter; WHA, water-soluble humic acid; HSL, humic-like substance; FAL, fulvic acid-like; HAL, humic acid-like. $r$ values were coefficients based on the results of Pearson's correlation analysis $(n=21){ }^{*}$ and ${ }^{* *}$ indicate significances at $P<0.05$ and $P<0.01$ levels, respectively. Decomposition rate of OMs was calculated by the contents of organic carbon dividing 540 days.

\subsection{Residual quantities and carbon released quantities of OMs in decomposition process}

The decomposition process of OMs could be divided into three stages, 0-90 days for a "quick decomposition period", 90-180 days for a "slow decomposition period", and 180-540 days for a 
"stable decomposition period" (Fig. 3). In 90 days, decomposition rate of OMs was over 70\%. In 540 days, residual quantities of CM, SM and MS decreased to 5.69, 6.11, and $6.53 \mathrm{~g}$ from the initial $20 \mathrm{~g}$, whereas those of MR, FG, and TL decreased to $8.05,8.84$, and $10.32 \mathrm{~g}$, respectively. Moreover, the decomposition rates of CM, SM, and MS (71.55\%, 68.16\%, and $68.21 \%$ ) were higher than those of MR, FG, and TL $(58.64 \%, 55.28 \%$, and $47.95 \%)$, respectively.

The trends of quantities of carbon released from OMs were first quickly increased and then tended to stable in decomposition process (Fig. 4). Quantity of carbon released from MS was higher than those of other OMs in each period. In 90 days, quantities of carbon released from OMs were over $65 \%$. In 540 days, quantities of carbon released from MS, TL, MR, FG, SM, and CM were $6.38,4.85,4.71,4.64,4.37$, and $3.80 \mathrm{~g}$, respectively.

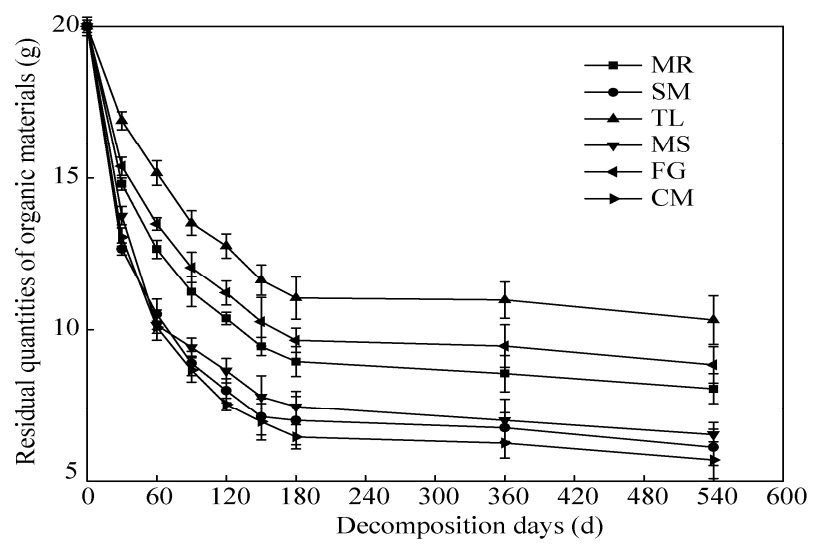

Fig. 3 Dynamic changes of residual quantities of OMs in decomposition process under different treatments. Error bars mean standard deviations.

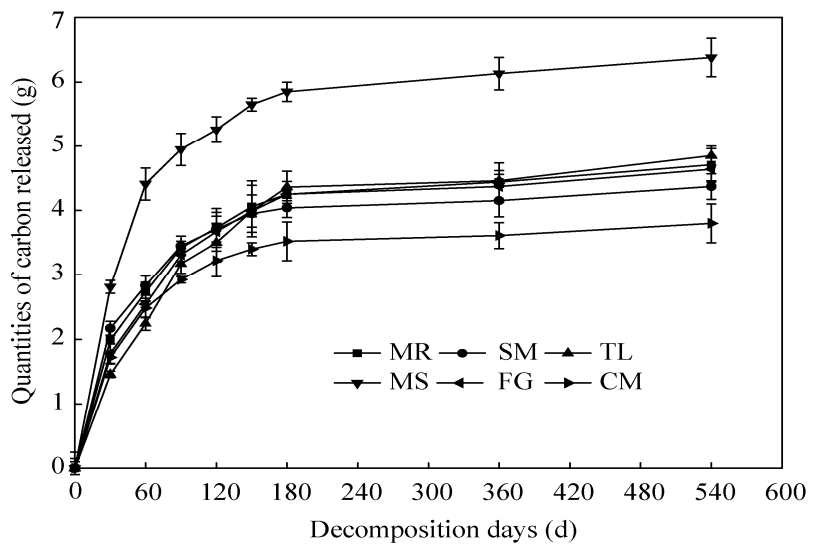

Fig. 4 Dynamic changes of quantities of carbon released from OMs in decomposition process under different treatments. Error bars mean standard deviations.

The changes of residual quantities of OMs in decomposition process could be fitted by the first-order kinetic equation $\left(y=a+b \times \mathrm{e}^{-k \times t}\right)$ (Table 5), with a higher correlation $\left(R^{2}>0.98\right) . k$ values of CM, SM and MS were higher, and required 61, 63 and 69 days to decompose one half, respectively. However, $k$ values of $\mathrm{MR}, \mathrm{FG}$, and TL were lower than those of other OMs, and required 117, 161 and even 590 days to decompose one half, respectively. The changes of quantities of carbon released from OMs in decomposition process could be fitted by the first-order kinetic equation $C_{t}=C_{0} \times\left(1-\mathrm{e}^{-k_{0} \times t}\right)$, with a higher correlation $\left(R^{2}>0.98\right)$. $C_{0}$ value of MS was the highest (6.11), and followed by TL (4.75), whereas those of CM and SM were lower (3.66 and 4.18, respectively). $k_{0}$ value of SM was the highest $(0.0203)$, and followed by MS (0.0194) and CM (0.0189), whereas that of TL was the lowest (0.0117). 
HU Juan et al.: Decomposition characteristics of organic materials and their effects on labile and...

Table 5 Fitted equation of residual quantities and carbon released quantities of OMs and decomposition days

\begin{tabular}{|c|c|c|c|c|c|c|c|}
\hline \multirow{2}{*}{ Treatment } & \multicolumn{4}{|c|}{$y=a+b \times \mathrm{e}^{-k \times t}$} & \multicolumn{3}{|c|}{$C_{t}=C_{0} \times\left(1-\mathrm{e}^{-k_{0} \times t}\right)$} \\
\hline & $a$ & $b$ & $k$ & $R^{2}$ & $C_{0}$ & $k_{0}$ & $R^{2}$ \\
\hline MR & 8.40 & 11.34 & 0.0162 & 0.9919 & 4.52 & 0.0160 & 0.9914 \\
\hline $\mathrm{CM}$ & 6.12 & 13.67 & 0.0206 & 0.9945 & 3.66 & 0.0189 & 0.9950 \\
\hline SM & 6.67 & 13.06 & 0.0218 & 0.9879 & 4.18 & 0.0203 & 0.9899 \\
\hline $\mathrm{TL}$ & 10.64 & 9.56 & 0.0127 & 0.9916 & 4.75 & 0.0117 & 0.9923 \\
\hline MS & 7.06 & 12.81 & 0.0209 & 0.9897 & 6.11 & 0.0194 & 0.9922 \\
\hline FG & 9.16 & 10.62 & 0.0151 & 0.9912 & 4.51 & 0.0146 & 0.9950 \\
\hline
\end{tabular}

Note: $R^{2}$ is determination coefficient; $y$ is residual quantity at time $t ; k$ is constant of decomposition rate calculated by the least-squares method, indicating the decomposing speed level; $b$ is mass lost; $a$ is asymptote value of $y$ when $t$ is $\propto$. $C_{t}$ is quantities of carbon released from organic material at time $t ; C_{0}$ is carbon mineralization potentials; $k_{0}$ is constant of carbon decomposition rate calculated by the least-squares method.

\subsection{Residual quantities of cellulose and lignin of OMs in decomposition process}

The trends of residual quantities of cellulose contents were quickly declined and then tended to stable in decomposition process, which were almost the same with the trends of residual quantities of OMs (Fig. 5). Cellulose contents of FG and TL quickly decomposed in 0-60 days, whereas those of MS, MR, CM, and SM quickly decomposed in 0-90 days. In 540 days, cellulose decomposition percentages of OMs followed the descending order $\mathrm{MS}>\mathrm{CM}>\mathrm{FG}>\mathrm{MR}>\mathrm{TL}>\mathrm{SM}$, and reached to $64.87 \%, 62.67 \%, 62.44 \%, 55.93 \%, 51.36 \%$ and $50.14 \%$, respectively.

Residual quantities of lignin contents of OMs increased in the early decomposition. Lignin contents of MS, CM, and SM increased mainly in 0-60 days, whereas those of TL, FG, and MR mainly increased in 0-90 days. Compared with lignin contents of initial OMs, in 540 days, lignin contents of TL, MS, MR, FG, SM and CM increased 26.77\%, 21.36\%, 19.14\%, 16.09\%, 11.84\% and $10.68 \%$, respectively.
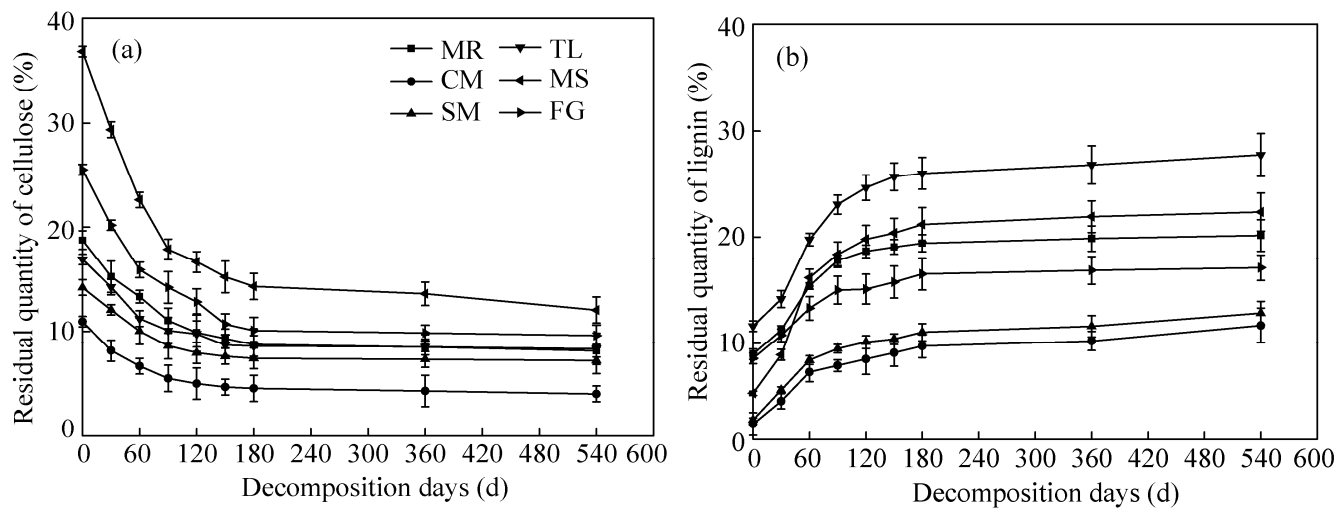

Fig. 5 Dynamic changes of residual quantities of cellulose (a) and lignin (b) contents of OMs in decomposition process

\subsection{Water-soluble organic matter of OMs in decomposition process}

Dynamic changes of water-soluble organic matter (WLOM) of OMs in decomposition process were presented in Table 6. WLOM contents of OMs basically declined in decomposition process, and only MS and TL increased in 90 days. WOM and WHA contents of OMs showed rising trends in 90 days, and WOM contents of MS, FG and MR significantly increased and sustained a longer time, whereas those of CM, SM and TL slightly increased and sustained a shorter time, in addition, WHA contents of MS increased the most compared with those of other OMs.

\subsection{Humic-like substance of OMs in decomposition process}

Dynamic changes of humic-like substance of OMs in decomposition process were shown in Table 7. There were rising trends of HSL and HAL contents in decomposition process. HSL and HAL contents of MS increased in 60 days, and reached the maximum values in 90 days. Moreover, HSL and HAL contents of MS were obviously higher than those of other OMs in each period. HSL and 
HAL contents of CM, SM, MR, TL, and FG increased in 90 days, and those of TL, MR and FG had a large increase.

Table 6 Dynamic changes of water-soluble organic matter of OMs in decomposition process

\begin{tabular}{|c|c|c|c|c|c|c|c|c|c|c|}
\hline \multirow{2}{*}{ OMs } & \multirow{2}{*}{ Components } & \multicolumn{9}{|c|}{ Decomposition days (d) } \\
\hline & & 0 & 30 & 60 & 90 & 120 & 150 & 180 & 360 & 540 \\
\hline \multirow{3}{*}{ MR } & WOM & $12.82 \pm 1.2$ & $8.98 \pm 0.18$ & $5.20 \pm 0.58$ & $7.11 \pm 0.51$ & $6.58 \pm 0.62$ & $4.44 \pm 0.26$ & $3.68 \pm 0.56$ & $3.43 \pm 0.16$ & $2.11 \pm 0.05$ \\
\hline & WLOM & $7.33 \pm 0.52$ & $4.16 \pm 0.06$ & $3.14 \pm 0.09$ & $2.76 \pm 0.13$ & $2.51 \pm 0.12$ & $1.94 \pm 0.08$ & $1.68 \pm 0.21$ & $1.49 \pm 0.08$ & $1.02 \pm 0.03$ \\
\hline & WHA & $5.49 \pm 0.26$ & $4.82 \pm 0.17$ & $2.06 \pm 0.10$ & $4.35 \pm 0.18$ & $4.07 \pm 0.21$ & $2.51 \pm 0.26$ & $2.00 \pm 0.16$ & $1.93 \pm 0.11$ & $1.09 \pm 0.08$ \\
\hline \multirow{3}{*}{$\mathrm{CM}$} & WOM & $15.55 \pm 2.27$ & $7.27 \pm 0.81$ & $5.49 \pm 0.34$ & $6.93 \pm 0.54$ & $5.08 \pm 0.15$ & $3.43 \pm 0.04$ & $3.21 \pm 0.13$ & $3.05 \pm 0.24$ & $2.03 \pm 0.10$ \\
\hline & WLOM & $6.47 \pm 0.43$ & $4.82 \pm 0.23$ & $3.93 \pm 0.16$ & $3.17 \pm 0.19$ & $2.92 \pm 0.06$ & $2.34 \pm 0.15$ & $2.20 \pm 0.17$ & $2.11 \pm 0.18$ & $1.64 \pm 0.05$ \\
\hline & WHA & $9.07 \pm 1.24$ & $2.45 \pm 0.03$ & $1.56 \pm 0.07$ & $3.76 \pm 0.27$ & $2.16 \pm 0.07$ & $1.09 \pm 0.09$ & $1.01 \pm 0.08$ & $0.94 \pm 0.06$ & $0.39 \pm 0.03$ \\
\hline \multirow{3}{*}{ SM } & WOM & $13.71 \pm 1.30$ & $6.23 \pm 0.87$ & $5.20 \pm 0.44$ & $5.46 \pm 0.55$ & $4.19 \pm 0.38$ & $3.83 \pm 0.21$ & $2.83 \pm 0.19$ & $2.56 \pm 0.26$ & $2.48 \pm 0.14$ \\
\hline & WLOM & $5.20 \pm 0.71$ & $4.57 \pm 0.34$ & $3.81 \pm 0.24$ & $3.30 \pm 0.13$ & $3.17 \pm 0.13$ & $2.86 \pm 0.17$ & $2.04 \pm 0.14$ & $1.95 \pm 0.13$ & $1.83 \pm 0.17$ \\
\hline & WHA & $8.50 \pm 0.47$ & $1.66 \pm 0.08$ & $1.40 \pm 0.07$ & $2.16 \pm 0.08$ & $1.02 \pm 0.04$ & $0.97 \pm 0.05$ & $0.79 \pm 0.06$ & $0.61 \pm 0.08$ & $0.65 \pm 0.02$ \\
\hline \multirow{3}{*}{$\mathrm{TL}$} & WOM & $11.04 \pm 1.26$ & $9.01 \pm 0.96$ & $6.60 \pm 0.78$ & $7.11 \pm 1.17$ & $5.71 \pm 0.43$ & $4.57 \pm 0.23$ & $4.32 \pm 0.37$ & $4.09 \pm 0.42$ & $3.28 \pm 0.13$ \\
\hline & WLOM & $4.91 \pm 0.25$ & $3.08 \pm 0.09$ & $2.57 \pm 0.07$ & $2.45 \pm 0.04$ & $2.38 \pm 0.06$ & $1.70 \pm 0.04$ & $1.64 \pm 0.26$ & $1.57 \pm 0.06$ & $1.42 \pm 0.06$ \\
\hline & WHA & $6.13 \pm 0.53$ & $5.93 \pm 0.37$ & $4.03 \pm 0.26$ & $4.66 \pm 0.54$ & $3.33 \pm 0.45$ & $2.87 \pm 0.28$ & $2.68 \pm 0.22$ & $2.52 \pm 0.08$ & $1.86 \pm 0.17$ \\
\hline \multirow{3}{*}{ MS } & WOM & $17.01 \pm 2.29$ & $7.87 \pm 0.66$ & $4.70 \pm 0.25$ & $7.11 \pm 0.28$ & $6.22 \pm 0.81$ & $4.06 \pm 0.15$ & $3.93 \pm 0.19$ & $3.51 \pm 0.15$ & $2.26 \pm 0.05$ \\
\hline & WLOM & $6.57 \pm 0.55$ & $3.33 \pm 0.27$ & $2.19 \pm 0.19$ & $2.25 \pm 0.17$ & $1.87 \pm 0.17$ & $1.74 \pm 0.16$ & $1.62 \pm 0.07$ & $1.30 \pm 0.17$ & $1.20 \pm 0.09$ \\
\hline & WHA & $10.44 \pm 2.22$ & $4.54 \pm 0.25$ & $2.51 \pm 0.15$ & $4.86 \pm 0.35$ & $4.35 \pm 0.26$ & $2.32 \pm 0.14$ & $2.31 \pm 0.18$ & $2.21 \pm 0.11$ & $1.06 \pm 0.08$ \\
\hline \multirow{3}{*}{ FG } & WOM & $15.86 \pm 2.31$ & $9.28 \pm 0.22$ & $6.62 \pm 0.51$ & $7.98 \pm 0.96$ & $6.71 \pm 0.11$ & $5.40 \pm 0.54$ & $4.82 \pm 0.26$ & $3.93 \pm 0.23$ & $2.81 \pm 0.17$ \\
\hline & WLOM & $7.68 \pm 1.18$ & $4.70 \pm 0.40$ & $4.06 \pm 0.26$ & $4.16 \pm 0.22$ & $3.93 \pm 0.16$ & $3.55 \pm 0.23$ & $3.11 \pm 0.38$ & $2.74 \pm 0.09$ & $2.55 \pm 0.11$ \\
\hline & WHA & $8.19 \pm 1.14$ & $4.58 \pm 0.38$ & $2.56 \pm 0.06$ & $3.82 \pm 0.16$ & $2.78 \pm 0.04$ & $1.85 \pm 0.07$ & $1.71 \pm 0.06$ & $1.19 \pm 0.04$ & $0.26 \pm 0.03$ \\
\hline
\end{tabular}

Note: WOM, Total water-soluble organic matter; WLOM, water-soluble litter-molecular organic matter; WHA, water-soluble humic acid. Mean \pm standard error.

Table 7 Dynamic changes of humic-like substance of OMs in decomposition process

\begin{tabular}{|c|c|c|c|c|c|c|c|c|c|c|}
\hline \multirow{2}{*}{ OMs } & \multirow{2}{*}{ Components } & \multicolumn{9}{|c|}{ Decomposition days (d) } \\
\hline & & 0 & 30 & 60 & 90 & 120 & 150 & 180 & 360 & 540 \\
\hline \multirow{3}{*}{ MR } & HSL & $7.93 \pm 1.20$ & $5.08 \pm 0.95$ & $3.17 \pm 1.13$ & $11.30 \pm 1.82$ & $9.01 \pm 1.63$ & $8.63 \pm 1.22$ & $7.36 \pm 0.85$ & $4.32 \pm 0.67$ & $3.32 \pm 0.39$ \\
\hline & FAL & $4.47 \pm 0.29$ & $4.06 \pm 0.32$ & $2.79 \pm 0.16$ & $4.95 \pm 0.33$ & $4.70 \pm 0.18$ & $4.19 \pm 0.24$ & $3.93 \pm 0.29$ & $3.55 \pm 0.15$ & $2.91 \pm 0.16$ \\
\hline & HAL & $3.46 \pm 0.22$ & $1.02 \pm 0.08$ & $0.38 \pm 0.17$ & $6.35 \pm 0.70$ & $4.31 \pm 0.34$ & $4.44 \pm 0.21$ & $3.43 \pm 0.18$ & $0.77 \pm 0.13$ & $0.41 \pm 0.08$ \\
\hline \multirow{3}{*}{$\mathrm{CM}$} & HSL & $6.16 \pm 1.30$ & $4.19 \pm 0.23$ & $2.67 \pm 0.06$ & $7.62 \pm 1.27$ & $7.87 \pm 0.83$ & $7.36 \pm 0.91$ & $6.28 \pm 0.54$ & $3.05 \pm 0.11$ & $2.05 \pm 0.05$ \\
\hline & FAL & $4.19 \pm 0.25$ & $2.79 \pm 0.05$ & $1.78 \pm 0.12$ & $2.73 \pm 0.06$ & $2.41 \pm 0.14$ & $2.28 \pm 0.10$ & $2.16 \pm 0.16$ & $2.05 \pm 0.08$ & $1.55 \pm 0.06$ \\
\hline & HAL & $1.97 \pm 0.06$ & $1.40 \pm 0.03$ & $0.89 \pm 0.05$ & $4.89 \pm 0.23$ & $5.46 \pm 0.46$ & $5.08 \pm 0.45$ & $4.12 \pm 0.31$ & $1.00 \pm 0.14$ & $0.50 \pm 0.03$ \\
\hline \multirow{3}{*}{ SM } & HSL & $8.19 \pm 1.18$ & $5.58 \pm 0.24$ & $3.05 \pm 0.10$ & $5.84 \pm 0.45$ & $5.20 \pm 0.62$ & $4.57 \pm 0.25$ & $4.19 \pm 0.38$ & $3.43 \pm 0.29$ & $2.43 \pm 0.61$ \\
\hline & FAL & $2.16 \pm 0.13$ & $1.78 \pm 0.06$ & $1.27 \pm 0.11$ & $1.52 \pm 0.04$ & $1.90 \pm 0.15$ & $1.78 \pm 0.09$ & $1.65 \pm 0.03$ & $1.40 \pm 0.04$ & $1.03 \pm 0.05$ \\
\hline & HAL & $6.03 \pm 0.40$ & $3.81 \pm 0.05$ & $1.78 \pm 0.08$ & $4.32 \pm 0.08$ & $3.30 \pm 0.03$ & $2.79 \pm 0.03$ & $2.54 \pm 0.04$ & $2.03 \pm 0.10$ & $1.40 \pm 0.03$ \\
\hline \multirow{3}{*}{$\mathrm{TL}$} & HSL & $10.28 \pm 1.21$ & $8.50 \pm 0.79$ & $5.08 \pm 0.47$ & $15.86 \pm 1.27$ & $10.53 \pm 1.21$ & $9.90 \pm 1.27$ & $8.96 \pm 1.19$ & $6.09 \pm 0.23$ & $4.09 \pm 0.16$ \\
\hline & FAL & $5.97 \pm 0.34$ & $4.82 \pm 0.46$ & $2.16 \pm 0.09$ & $6.22 \pm 0.75$ & $4.70 \pm 0.26$ & $3.68 \pm 0.18$ & $3.47 \pm 0.15$ & $2.79 \pm 0.14$ & $1.79 \pm 0.11$ \\
\hline & HAL & $4.32 \pm 0.26$ & $3.68 \pm 0.35$ & $2.92 \pm 0.13$ & $9.65 \pm 0.76$ & $5.84 \pm 0.24$ & $6.22 \pm 0.84$ & $5.49 \pm 0.46$ & $3.30 \pm 0.27$ & $2.30 \pm 0.08$ \\
\hline \multirow{3}{*}{ MS } & HSL & $17.45 \pm 2.21$ & $13.20 \pm 2.17$ & $17.77 \pm 1.16$ & $620.43 \pm 2.37$ & $17.26 \pm 1.36$ & $15.99 \pm 1.35$ & $13.96 \pm 2.24$ & $9.58 \pm 0.89$ & $6.58 \pm 0.46$ \\
\hline & FAL & $9.90 \pm 1.90$ & $7.87 \pm 0.72$ & $6.73 \pm 0.17$ & $7.62 \pm 0.20$ & $7.23 \pm 0.61$ & $5.97 \pm 0.46$ & $4.82 \pm 0.11$ & $3.46 \pm 0.16$ & $2.49 \pm 0.07$ \\
\hline & HAL & $7.55 \pm 0.85$ & $5.33 \pm 0.36$ & $11.04 \pm 1.22$ & $12.82 \pm 1.25$ & $10.03 \pm 1.33$ & $10.02 \pm 0.91$ & $9.14 \pm 0.71$ & $6.12 \pm 0.61$ & $4.09 \pm 0.52$ \\
\hline \multirow{3}{*}{ FG } & HSL & $14.91 \pm 1.17$ & $1.93 \pm 1.23$ & 7. $36 \pm 1.21$ & $14.47 \pm 1.30$ & $11.45 \pm 1.21$ & $10.77 \pm 1.34$ & $8.78 \pm 1.19$ & $7.50 \pm 0.88$ & $5.50 \pm 0.63$ \\
\hline & FAL & $8.25 \pm 1.16$ & $6.60 \pm 0.76$ & $5.71 \pm 0.83$ & $6.55 \pm 0.45$ & $6.23 \pm 0.64$ & $5.58 \pm 0.47$ & $4.98 \pm 0.56$ & $4.08 \pm 0.27$ & $3.27 \pm 0.17$ \\
\hline & HAL & $6.66 \pm 0.64$ & $5.33 \pm 0.31$ & $1.65 \pm 0.06$ & $7.92 \pm 0.78$ & $5.22 \pm 0.57$ & $5.19 \pm 0.41$ & $3.80 \pm 0.16$ & $3.42 \pm 0.13$ & $2.23 \pm 0.03$ \\
\hline
\end{tabular}




\section{Discussion}

Continuous application of OMs could influence the levels of soil organic matter and the quality of some or all of its pools (Cadisch and Giller, 2000). Many studies have shown that OMs played a positive role in altering soil environment and promoting SOC storage (Liu et al., 2005; Purakayastha et al., 2008; Banger et al., 2010). Wang (2014) found that LOC and POC contents after the application of straw were significantly higher in semi-arid soil than in sub-humid soil. Thus, the result illustrated that the effects of OMs on labial organic carbon might be greater in the semi-arid soil. In this study, compared with no OMs (CK), LC and RC contents in soil significantly increased $(P<0.01)$ after the continuous application of OMs for 2 years. Moreover, LC and RC contents were $3.2 \%-8.6 \%$ and $5.0 \%-9.4 \%$ higher in 2016 than in 2015 , respectively, being consistent with the result of Wang (2014), who found that the SOC, light fraction organic carbon (LOC), and particulate organic carbon (POC) contents of straw treatment under plastic mulch were higher in 2010 than in 2009, and were significantly higher than that of no straw treatment.

The application of OMs, and different sources and decomposing degrees of OMs were all affected the SOC fractions under plastic film mulch (Li et al., 2009). Furthermore, Vanlauwe et al. (2005) indicated that short-term carbon dynamics was controlled by the quality parameters of OMs inputted, such as lignin, N, and polyphenol contents and this funding was confirmed further by Mandal et al. (2007) and Singh et al. (2009), who suggested that the quality of OMs was an important factor on agricultural soil carbon changes besides the amount of injected carbon. In this study, the amount of carbon inputted was equivalent in different OMs treatments. Therefore, the variation of SOC fractions mainly depended on the nature of OMs. Hence, a correlation analysis was conducted to explore the relationships between OMs compositions and SOC fractions. Results indicated that the lignin and polyphenol contents in OMs played important roles in SOC and RC contents in soil, which was consistent with the result of Gentile et al. (2010). Puttaso et al. (2013) found that lignin and polyphenols were more resistant and difficult to decompose compared with the cellulose and hemicellulose, and thus were benefited to the SOC improvement. Similarly, Trinsoutrot et al. (2000) indicated that the residues with higher concentrations of lignin and polyphenols might be more stable as an important component of SOC by biochemical processes due to the highly recalcitrant lignin. Moreover, in this study, we found that the most important factors affecting the SOC and RC contents can be attributing to the WOM, WHA, HSL, and HAL contents in OMs.

The decomposition rate was an important index for its role in maintaining and improving soil organic matter distribution and soil fertility ( $\mathrm{Li}$ et al., 2015). In this study, we found that the decomposition rate of OMs was in the following descending order $\mathrm{CM}>\mathrm{SM}>\mathrm{MS}>\mathrm{MR}>\mathrm{FG}>\mathrm{TL}$, moreover, decomposition rates of CM, SM and MS were obviously higher than those of MR, FG and TL. Gao et al. (2010) and Liang et al. (2011) showed that water soluble organic carbon (WOC) contents in soil after application of animal manures were higher than those of straw. In this study, LC contents in soil after the applications of CM and SM were significantly higher than those of other OMs, and followed by MS, whereas that of TL was the lowest. Similarly, LC/SOC ratios after the applications of $\mathrm{CM}$ and SM were higher, which implied that applications of CM and SM were more in favor of SOC mineralization and turnover. Moreover, the decomposition rate of OMs was positively related with LC content and LC/SOC ratio. Therefore, applications of CM and SM significantly increased the LC contents and LC/SOC ratios mainly due to their higher decomposition rates. On the other hand, SOC and RC contents in soil after the applications of TL and MS were significantly higher than those of other OMs, and RC/SOC ratios were similarly higher, which implied that applications of TL and MS were more in favor of SOC storage. The higher RC and SOC contents of TL and MS treatments can be attributed to the higher lignin/N ratio, lignin and polyphenols contents in TL and MS, which is not consistent with the result of Long et al. (2015), who found that SOC content of pig manure treatment in silt loam was significantly higher than those of straw treatment. The inconsistence might be attributed to the various soil type and environment. 
Wang et al. (2014) and Liu et al. (2014) researched the decomposition rate of maize straw in a semi-arid and dryland soil under plastic film mulch condition using nylon mesh bags burying method, and they found that plastic film mulch could promote carbon mineralization. Therefore, application of OMs in semi-arid soils under a long-term plastic film mulch condition is necessary. In this study, application of six kinds of OMs significantly increased the SOC, LC, and RC contents. However, the variations of $\mathrm{LC}$ and $\mathrm{RC}$ contents, $\mathrm{LC} / \mathrm{SOC}$ ratio, and $\mathrm{RC} / \mathrm{SOC}$ ratio were significant different among the six kinds of OMs treatments. For example, decomposition rate of MS was higher, and the WOM, WHA, HSL, and HAL contents in MS were the highest, and the more lignin derivatives, WHA, and HAL polymers were found in decomposition process. Thus, MS was recommended to use under plastic mulch and drip irrigation in semi-arid soils.

\section{Conclusions}

A two-year of field experiment has showed that LC and RC contents in soil after the continuous application of OMs significantly increased. LC and RC contents were $3.2 \%-8.6 \%$ and $5.0 \%-9.4 \%$ higher in 2016 than in 2015 . LC contents after the applications of CM and SM were significantly higher, and followed by MS, whereas that of TL was the lowest. In addition, $\mathrm{LC} / \mathrm{SOC}$ ratios after the applications of $\mathrm{CM}$ and SM were significantly higher as well. SOC and $\mathrm{RC}$ contents in soil after the applications of TL and MS were significantly higher, whereas those of $\mathrm{CM}$ and SM were relatively lower. In addition, $\mathrm{RC} / \mathrm{SOC}$ ratios after the applications of TL and MS were higher as well. In conclusion, the application of MS in the semi-arid soil under a long-term plastic mulch and drip irrigation condition could not only improve soil fertility, but also enhance soil carbon sequestration.

\section{Acknowledgements}

This research was supported by the National Key R\&D Program of China (2017YFD0201801) and the Research Foundation of the Science \& Technology Agency of Jilin Province, China (20150203004NY).

\section{Reference}

Banger K, Toor G S, Biswas A, et al. 2010. Soil organic carbon fractions after 16-years of applications of fertilizers and organic manure in a Typic Rhodalfs in semi-arid tropics. Nutrient Cycling in Agroecosystems, 86(3): 391-399.

Cadisch G, Giller K E. 2000. Soil organic matter management: the role of residue quality in carbon sequestration and nitrogen supply. In: Rees R M, Ball B, Campbell C D, et al. Sustainable Management of Soil Organic Matter. Wallingford, UK: CAB International, 97-111.

Chen A Q, Fu B, Lu Y, et al. 2015. Exogenous organic materials applied to paddy field improving soil microbial biomass $\mathrm{C}, \mathrm{N}$ and dissolved organic C, N. Transactions of the Chinese Society of Agricultural Engineering, 31(21): 160-167. (in Chinese)

Cookson W R, Abaye D A, Marschner P, et al. 2005. The contribution of soil organic matter fractions to carbon and nitrogen mineralization and microbial community size and structure. Soil Biology and Biochemistry, 37(9): 1726-1737.

Du Z L, Ren T S, Hu C S, et al. 2013. Soil aggregate stability and aggregate-associated carbon under different tillage systems in the North China plain. Journal of Integrative Agriculture, 12(11): 2114-2123.

Gao Z X, Zhou J B, Wang X, et al. 2010. Effects of different fertilizer treatments on content and characteristics of dissolved organic carbon in soil. Acta Pedologica Sinica, 47(1): 115-121. (in Chinese)

Gentile R, Vanlauwe B, Kavoo A, et al. 2010. Residue quality and N fertilizer do not influence aggregate stabilization of C and $\mathrm{N}$ in two tropical soils with contrasting texture. Nutrient Cycling in Agroecosystems, 88(1): 121-131.

Gougoulias C, Clark J M, Shaw L J. 2014. The role of soil microbes in the global carbon cycle: tracking the below-ground microbial processing of plant-derived carbon for manipulating carbon dynamics in agricultural systems. Journal of the Science of Food and Agriculture, 94(12): 2362-2371.

Haubensak K A, Hart S C, Stark J M. 2002. Influences of chloroform exposure time and soil water content on C and N release in forest soils. Soil Biology and Biochemistry, 34(11): 1549-1562.

Haynes R J. 2005. Labile organic matter fractions as central components of the quality of agricultural soils: an overview. Advances in Agronomy, 85: 221-268.

Huygens D, Rütting T, Boeckx P, et al. 2007. Soil nitrogen conservation mechanisms in a pristine south Chilean Nothofagus 
forest ecosystem. Soil Biology and Biochemistry, 39(10): 2448-2458.

Jiang Y, Shi C Y, Wang Z Z, et al. 2014. Effects of plastic film mulching on arable layer soil temperature, moisture and yield of sweet potato. Chinese Journal of Eco-Agriculture, 22(6): 627-634. (in Chinese)

Knoblauch C, Maarifat A A, Pfeiffer E M, et al. 2011. Degradability of black carbon and its impact on trace gas fluxes and carbon turnover in paddy soils. Soil Biology and Biochemistry, 43(9): 1768-1778.

Lal R. 2004. Soil carbon sequestration impacts on global climate change and food security. Science, 304(5677): $1623-1627$.

Li H, Wang Z H, Wang X N, et al. 2007. Effects of cultivation types on yield formation and nitrogen accumulation and remobilization for winter wheat. Journal of Agro-Environment Science, 26(1): 369-374. (in Chinese)

Li L L, Wang Z H, Wang X N, et al. 2009. Effects of soil-surface mulching on organic carbon, inorganic carbon and light fraction organic carbon in dryland soil. Plant Nutrition and Fertilizer Science, 15(2): 478-483. (in Chinese)

Li X H, Guo H H, Zhu Z L, et al. 2016. Effects of different straw return modes on contents of soil organic carbon and fractions of soil active carbon. Transactions of the Chinese Society of Agricultural Engineering, 32(9): 130-135. (in Chinese)

Li S P, Cai Z C, Yang H, et al. 2009. Effects of long-term fertilization and plastic film covering on some soil fertility and microbial properties. Acta Ecologica Sinica, 29(5): 2489-2498. (in Chinese)

Li Z P, Liu M, Jiang C Y. 2015. Decomposition, accumulation and distribution of soil organic matter in typical red soil region of China. Soils, 47(2): 220-228. (in Chinese)

Liang Y, Han X Z, Song C, et al. 2011. Impacts of returning organic materials on soil labile organic carbon fractions redistribution of mollisol in northeast China. Scientia Agricultura Sinica, 44(17): 3565-3574. (in Chinese)

Liang Y. 2012. Effect of organic amendments application on dynamics, fractions and structural properties of soil organic matter in black soil. PhD Dissertation. Changchun: Northeast Institute of Geography and Agroecology, Chinese Academy of Sciences. (in Chinese)

Liu S W, Zhang Y J, Zong Y J, et al. 2016. Response of soil carbon dioxide fluxes, soil organic carbon and microbial biomass carbon to biochar amendment: a meta-analysis. Global Change Biology Bioenergy, 8(2): 392-406.

Liu X B, Liu J D, Xing B S, et al. 2005. Effects of long-term continuous cropping, tillage, and fertilization on soil organic carbon and nitrogen of black soils in China. Communications in Soil Science and Plant Analysis, 36(9-10): 1229-1239.

Liu X E, Li X G, Hai L, et al. 2014. Film-mulched ridge-furrow management increases maize productivity and sustains soil organic carbon in a dryland cropping system. Soil Science Society of America Journal, 78(4): 1434-1441.

Long P, Sui P, Gao W S, et al. 2015. Effects of agricultural organic wastes incorporation on soil organic carbon and microbial carbon. Journal of China Agricultural University, 20(3): 153-160. (in Chinese)

Loveland P, Webb J. 2003. Is there a critical level of organic matter in the agricultural soils of temperate regions: a review. Soil and Tillage Research, 70(1): 1-18.

Mandal B, Majumder B, Bandyopadhyay P K, et al. 2007. The potential of cropping systems and soil amendments for carbon sequestration in soils under long-term experiments in subtropical India. Global Change Biology, 13(2): 357-369.

Manna M C, Swarup A, Wanjari R H, et al. 2005. Long-term effect of fertilizer and manure application on soil organic carbon storage, soil quality and yield sustainability under sub-humid and semi-arid tropical India. Field Crops Research, 93(2-3): 264-280.

McLauchlan K K, Hobbie S E. 2004. Comparison of labile soil organic matter fractionation techniques. Soil Science Society of America Journal, 68(5): 1616-1625.

Meijboom F W, Hassink J, Van Noordwijk M. 1995. Density fractionation of soil macroorganic matter using silica suspensions. Soil Biology and Biochemistry, 27(8): 1109-1111.

Meng Q F, Yang J S, Yao R J, et al. 2013. Fertilization affects biomass production of Suaeda salsa and soil organic carbon pool in east coastal region of China. Journal of Integrative Agriculture, 12(9): 1659-1672.

Müller C, Stevens R J, Laughlin R J. 2004. A N ${ }^{15}$ tracing model to analyze N transformations in old grassland soil. Soil Biology and Biochemistry, 36(4) : 619-632.

Nandwa S P. 2001. Soil organic carbon (SOC) management for sustainable productivity of cropping and agro-forestry systems in Eastern and Southern Africa. Nutrient Cycling in Agroecosystems, 61: 143-158.

Plaza-Bonilla D, Álvaro-Fuentes J, Cantero-Martínez C. 2014. Identifying soil organic carbon fractions sensitive to agricultural management practices. Soil and Tillage Research, 139: 19-22.

Purakayastha J, Rudrappa L, Singh D, et al. 2008. Long-term impact of fertilizers on soil organic carbon pools and sequestration rates in maize-wheat-cowpea cropping system. Geoderma, 144(1-2): 370-378.

Puttaso A, Vityakon P, Rasche F, et al. 2013. Does organic residue quality influence carbon retention in a tropical sandy soil? Soil Science Society of America Journal, 77(3): 1001-1011. 
Schmidt M W I, Torn M S, Abiven S, et al. 2011. Persistence of soil organic matter as an ecosystem property. Nature, 478(7367): 49-56.

Singh K P, Ghoshal N, Singh S. 2009. Soil carbon dioxide flux, carbon sequestration and crop productivity in a tropical dryland agroecosystem: influence of organic inputs of varying resource quality. Applied Soil Ecology, 42(3): 243-253.

Sparling G, Schipper L. 2004. Soil quality monitoring in New Zealand: trends and issues arising from a broad-scale survey. Agriculture, Ecosystems \& Environment, 104(3): 545-552.

Trinsoutrot I, Recous S, Bentz B, et al. 2000. Biochemical quality of crop residues and carbon and nitrogen mineralization kinetics under nonlimiting nitrogen conditions. Soil Science Society of America Journal, 64(3): 918-926.

Troy S M, Lawlor P G, O’Flynn C J, et al. 2013. Impact of biochar addition to soil on greenhouse gas emissions following pig manure application. Soil Biology and Biochemistry, 60: 173-181.

Turkmen N, Sari F, Velioglu Y S. 2006. Effects of extraction solvents on concentration and antioxidant activity of black and black mate tea polyphenols determined by ferrous tartrate and Folin-Ciocalteu methods. Food Chemistry, 99(4): 835-841.

Van Soest P J. 1963. Use of detergents in the analysis of fibrous feeds. II. A rapid method for the determination of fiber and lignin. Journal of the Association of Official Agricultural Chemists, 46(5): 829-835.

Vanlauwe B, Gachengo C, Shepherd K, et al. 2005. Laboratory validation of a resource quality-based conceptual framework for organic matter management. Soil Science Society of America Journal, 69(4): 1135-1145.

Walkley A, Black C A. 1934. Acid extractable $\mathrm{Zn}$ in soil in relation to the occurrence of Zn deficiency symptoms of corn: A method of analysis. Soil Science Society of America Journal, 12:143-148.

Wang Y P. 2014. Effect of straw returning and plastic film mulching coupling on maize yield and the balance of organic matter in the Loess Plateau. PhD Dissertation. Lanzhou: Lanzhou University. (in Chinese)

Wang Y P, Li X G, Hai L, et al. 2014. Film fully-mulched ridge-furrow cropping affects soil biochemical properties and maize nutrient uptake in a rainfed semi-arid environment. Soil Science and Plant Nutrition, 60(4): 486-498. (in Chinese)

Wu J G, Lü Y, Wang M H, et al. 2004. Study on decomposition of organic fertilizers by FTIR. Plant Nutrition and Fertilizer Science, 10(3): 259-266. (in Chinese)

Yin T, He W Q, Yan C R, et al. 2014. Effects of plastic mulching on surface of no-till straw mulching on soil water and temperature. Transactions of the Chinese Society of Agricultural Engineering, 30(19): 78-87. (in Chinese)

Yu W S, Li G H, Wang B S, et al. 2015. Component characteristics of soil labile and recalcitrant carbon under long-term different fertilization systems in eastern China. Plant Nutrition and Fertilizer Science, 21(3): 675-683. (in Chinese)

Zhang X B, Xu M G, Zhang W J, et al. 2011. Characteristics of $\mathrm{CO}_{2}$ emission and microbial biomass dynamics after adding various organic materials in red soil. Scientia Agricultura Sinica, 44(24): 5013-5020. (in Chinese) 